\title{
Earthquake impact on settlements: the role of urban and structural morphology
}

\author{
M. Bostenaru Dan and I. Armas \\ Center for Risk Studies, Space Modeling and Dynamics of Terrestrial and Coastal Systems, Faculty of Geography, \\ University of Bucharest, Bucharest, Romania
}

Correspondence to: M. Bostenaru Dan (maria.bostenaru-dan@alumni.uni-karlsruhe.de)

Received: 19 March 2015 - Published in Nat. Hazards Earth Syst. Sci. Discuss.: 19 May 2015

Revised: 21 September 2015 - Accepted: 5 October 2015 - Published: 12 October 2015

\begin{abstract}
This study is aimed to create an alternative to the classical GIS representation of the impact of earthquake hazards on urban areas. To accomplish this, the traditional map was revised, so that it can cope with contemporary innovative ways of planning, namely strategic planning. As in the theory of fractals, the building dimension and the urban neighbourhood dimension are addressed as different geographic scales between which lessons for decisions can be learned through regression. The interaction between the two scales is useful when looking for alternatives, for the completion of a GIS analysis, and in choosing the landmarks, which, in the case of hazards, become strategic elements in strategic planning. A methodology to innovate mapping as a digital means for analysing and visualising the impact of hazards is proposed. This method relies on concepts from various geography, urban planning, structural engineering and architecture approaches related to disaster management. The method has been tested at the building scale for the N-S Boulevard in Bucharest, Romania, called Magheru. At the urban scale, an incident database has been created, in which the case study for the building level can be mapped. The paper presented is part of a larger research work, which addresses decision making using the framework shown here. The main value of the paper is in proposing a conceptual framework to deconstruct the map for digital earthquake disaster impact analysis and representation. The originality of the concept consists in the representation of elements at different scales considered to be of different levels of importance in the urban tissue, according to the analysis to be performed on them.
\end{abstract}

\section{Introduction}

In a dynamic built-up environment, which is characterised by increasing disaster events (Raschky, 2008), a better performing visualisation tool is of great importance for risk mitigation purposes. This paper is about developing ways of multiscale mapping exemplified for the earthquake hazard in Bucharest, as a mean of visualisation and analysis of a hazard impact. The focus is on how earthquake damage is visualised and analysed on maps and not on the vulnerability of the elements at risk. Innovation has been practiced for centuries on paper maps, but today, in the digital age and with planet Earth becoming an urban environment, the key concepts in mapping should be translated with an application to urban planning. This paper presents a methodology to obtain the components of a multiscale visualisation approach with an application to the spatial analysis of the impact of hazards for strategic planning.

The key concepts build upon are resilience, strategic planning, 4-D city models, mental maps, urban morphology, morphogenesis and macro-elements. These concepts have been developed independently by their authors. The innovation in this paper includes linking them into the general methodological framework presented in this paper. In this study, it is looked at the most evolved form of reaction to disasters: resilience. Resilience planning is the operational dimension in risk management, while the support of urban morphology represents the organisational dimension of risk management. Resilience has been approached in this context by the European project RISK UE (Mouroux and Le Brun, 2006), which identified strategic elements in different disaster phases (normal, preparedness, reconstruction). The normal phase, in considering preventive planning, can be divided into mitiga- 
tion and resilience; hence, Bostenaru Dan (2005) approached the urban planning types which correspond to the phases of the disaster planning cycle of reconstruction, preparedness, mitigation and resilience by providing examples of how these historically defined coping approaches now build (action components) layers, ranging from the simplest (reconstruction) to the most complex (resilience). For a detailed view of the interaction between resilience and morphology, two scales are considered: the urban scale (urban morphology) and the building scale (structural morphology). At the building scale, the International Association of Shells and Spatial Structures approach offers us a wide range of views on structural morphology, from that of Bögle (2004), who builds on morphology as historically understood by Goethe, up to the contemporary design approach of the computational morphology of building structure, which is inspired by organic forms from biology. In both, the structure of the building grows organically from the way that forces are led on their way to being transmitted to the foundation. In this paper, Christopher Alexander's (1977) dialogue between scales is envisaged. In his approach of organically determining the structure, Alexander (1977) went further, considering three scales: city, building, and element. Alexander's (1977) approach zooms from the city scale towards the building by describing patterns of favourable design situations, which can be used in the proposed "language" to compose a new situation. The building (structural) or urban morphology is an aggregate of these patterns. Alexander (1977) also employed a complex network in his Pattern Language, moving away from tradition: the relationship between patterns is a network, without having a map as its basis, and it is based on a mathematical view that was, at that time, similar to HTML. A challenge is how to map relationships between different scales, such as there are in Alexander (1977).

\section{Review of the main concepts used in this study}

In the following paragraphs reference will be made in more detail to the main concepts involved in this study. In urban planning, morphology refers, in particular, to the relationship between the built space and the free space, between buildings, parcels, and streets. Organically grown cities differ from the grid in pre-planned cities, in reality or in computer games. If the method developed by Lynch (1960) for a street network is followed, another kind of landmark can be identified, as there is reference to the particular case of visualising hazard impact, and not generally to the legibility of the city. Chirvasie (1995) placed organically grown landmarks, as attractors, in the middle of man-made islands in the historic centre of Bucharest; according to Chirvasie (1995), this is the only shape to which this method applies. The modification of the street network is dictated by the interaction of the network with these attractors, following fractal rules.
In Romania, urban morphology, in dialogue with risk situations, has also been addressed by Florescu (2009). In Florescu's (2009) work, the city can be seen, in a systemic approach, as an organism, and its discontinuities put vulnerability and context into connection. Florescu (2009) applied systemic theory to risks. Systemic theory means seeing the urban organism as a system. This system can be analysed using models. They concern the urban theories, structure and image. Later on, the image of the city and its implications for this research is discussed. According to systemic theory, in a dialogue between contents (led by the urban or structural forces) and container (urban or constructive structure) at the building level, the space is related to structure, and at the urban level, urban life is related to the urban image. In the context of this study, also the systemic theory is included, because the two dimensions (the procedural and the physical bases) correspond to the resilience (operational) and the morphology (organisational) of a city, as mentioned at the beginning of the article.

In the following, a review of several approaches will be performed, showing the transition between systemic analysis and strategic planning. These concepts have not been connected so far; such a connection is part of the contribution in this paper. Salewski's (2011) work thus introduces the notion of strategy in the case of disasters, which works as a basis for strategic planning. It compares the works of Kahn (1962) and Debord (1957). Kahn (1962) introduced and later developed the concept of scenario, analysing possible future scenarios, which would later move from the military into numerous fields as the basis for so-called "strategies" (Salewski, 2011). For this work, the introduction in the 1990s of the concept into urban planning, as strategic planning, is the most important factor, and it will be explained how it is used in this methodology. If Kahn (1962) thought about the unthinkable, Debord (1957) relied on visualising an invisible reality when developing a new concept of a map. The Naked City map (Debord, 1957) is a way of applying the "derivé" concept from Debord (1955) to deconstruct the map. "Derivé" was a situationist way of visualising the invisible, namely a technique describing the "irrational drifting through the city that would help the protagonist to follow the ways of his or her subconsciousness" (Salewski, 2011). Harley (1989) debated about deconstructing the map, from the classical view to representing systemic relationships. For this research, it is important that the deconstructed map of Debord (1957) is a way of reading the urban morphology, as Lynch (1960) explains.

Thus following the approach by Lynch (1960) of the image of the city as mental map is also a way of visualising the "heritage habitat", the mental map which would help inhabitants to effectively connect in case of reconstruction. The notion was introduced by Gociman in 2006, and mentioned it in relation to Alexander's (1977) phenomenological approach. The elements of the "heritage habitat" are items of cultural heritage. Cultural heritage is a valuable asset in it- 
self, but also because of its contribution to the creation of the identity of places. The study area in this paper is a protected zone in Bucharest, and hence heritage is important. Interventions have to be made to preserve cultural heritage in all phases of the disaster cycle: from the preventive retrofit to the reconstruction. This heritage contributes to form a mental map that the inhabitants have, which would help them to effectively connect in case of reconstruction. The paper shows which items from the locals' perception such as in Lynch (1960) and Debord can be included in the prioritisation. Even more, based on the proposed methods, a local seismic culture can be created and recorded for the interwar buildings in Bucharest.

If looked in detail at research about what can be the strategic elements in disaster management that are discussed, they are landmarks, according to the seminal work of Lynch (1960) on the image of the city. Bostenaru Dan (2004a) detailed a retrofit decision according to the analysis of an urban quarter, following Lynch's principles. In Gociman (2006), landmarks of the mental map are defined by architectural history, but also, green security nodes, a new type of strategic element which can be connected to the lost green spaces of the area. One example of how reconstruction after disasters has been wrongly done is the reconstruction after the 2009 earthquake in L'Aquila, Italy. Examples of how this was well done are the villages of Kolontar and Devecser in Hungary (after a chemical accident) in 2010 or Corbeni in Romania (after a flood) in 1940, as previous research of the first author shows (Bostenaru Dan, 2014). Also the Lynch analysis (1960) can decide which landmarks to keep in reconstruction efforts, as it happened in case of post1755 Lisbon (Bostenaru and Panagopoulos, 2014). Apart from the above-mentioned aspects, focus is also on the link between the perception studies of Lynch and the mapping method of Guy Debord in psychogeography (Bassett, 2004; Bridger, 2014; Darby, 2013; de Souza e Silva and Hjorth, 2009; Smith, 2013; Tesser, 2012; Travis, 2013, 2014; Wiley, 2010). In Bostenaru Dan and Dill (2014) the same study site was explored by walking. Walking plays a role also in Rapid Visual Screening for earthquake vulnerability (FEMA, 2015) and also in digital representation (subject of this paper) as the referred mobile apps show, and it has been recently connected by the DESURBS project again to disaster security research through some developed mobile apps (DESURBS, 2015). Lynch (1960) was never linked to Debord as far as the authors know, but the above named papers connect the method of derive (drift) to boundaries (an element at Lynch, 1960) and their identification, as well as to identity creation, which is a key concept in the heritage habitat (Gociman, 2006).

As mentioned, this study also zooms between scales. At different scales, maps contain different information. At the building level, this information is detailed, and it goes into three dimensions. To be able to visualise and analyse this kind of information, a morphogenesis of the building has to be done. The research is based, apart from the concept of morphogenesis at this scale, on the concept of macroelements (Lagomarsino, 1998), which will be detailed in relation to morphology. If morphology is the study of the form, morphogenesis is the way in which this form is generated.

If the city, in the aforementioned biological view, is seen as an organism, then urban activities represent the contents and build the basis for urban life. Morphogenesis can be applied in this sense also to building structures, as in case of computational morphology (Ohmori et al., 2005). In this case, morphogenesis comprises the elimination of the parts from a geometrical solid which does not serve the load of forces, and thereby, the shape is defined. This "shape" is related to what Alexander (1997) proposed at the building level. At the urban level, this is defined by the shaping of the public space of the streets in organic cities, which are not pre-planned, and are developing in a fractal way (see Chirvasie, 1995). Fractal analysis is a matter of future research, because it establishes the link between the part and the whole, between the building and the urban area, for example. If this is a structural way of looking at morphogenesis to define the structural morphology, there is also a building morphology, which refers to the architectural characteristics. A macro-element is a complex of building elements which present a unitary behaviour in the case of an earthquake. The failure modes of macro-elements can be seen separately, and they describe the performance level of the building. Lagomarsino's (1998) macro-elements are, however, not based on the organic shape, but on the geometric shape that can be seen through the morphogenesis proposed by Ioan (2012). The building is divided into complexes of structural parts (such as the roof, the tower, etc.) which can collapse during an event. The method of macro-elements is a detailed method for structural analysis which cannot be applied for large urban areas but just for selected buildings. To prioritise the choice, it is proposed to apply it for the landmarks, according to Lynch, or the nodes of the complex network, so that the latter will be used in the digital map. The macro-elements have also been employed in the aforementioned RISK UE project for monumental buildings such as churches. The strategic elements of the city/urban zones, which are defined according to the RISK UE project approach for different stages of planning, are to be modelled in a more detailed way: morphogenesis. In morphogenetic modelling, the 3-D representation of the shape of the building considers the whole cycle of structural resistance and structural collapse as a macro-element. Bostenaru Dan and Panagopoulos (2014) elaborated on the morphogenesis of landmarks for the digital representation of the impact of the 1755 Lisbon earthquake, by extending the silhouette 2-D model into a 3-D model. In the current study, which extends this previous research, it was aimed to develop complex networks of strategic elements, instead of the urban route of Bostenaru Dan and Dill (2014), without fully abandoning the landscape design configuration of alternative pedestrian routes in the area around the $\mathrm{N}-\mathrm{S}$ Magheru 
Boulevard in Bucharest. The study in this paper introduces the connection of the morphogenesis, which is seen as architectural language development, to the representation of earthquake resilient or earthquake vulnerable building parts in the macro-elements. The classification in earthquake resilient or earthquake vulnerable building parts comes from how building elements are classified in the World Housing Encyclopedia (WHE, 2015). Retrofit elements are considered from the stage of building survey/archive research, through structural simulation (pushover or dynamic analysis) up to devices computation of repair/replacement costs. The building survey part is relevant for this paper, as data were collected that way for the N-S Magheru Boulevard in Bucharest.

Depending on the scale and the analysis goals, the morphogenesis is determined either by urban forces or by physical forces (gravity, earthquake) acting on the structure. In the mapping in this study, such forces are represented in a graph. Innovatively presented in Debord (1957), today, the graph is present as a vector in the representation of complex networks. In this study, photographs of disasters are mapped and analysed as a complex network. The street network is also mapped as a graph to visualise the urban routes which are their correspondents in the physical space. Eisenman (1999) worked with a simplified version of a graph which did not include vectors, but only the geometrical dimensions of these flows. Thus, Eisenman (1999) approaches the space looking at how space is connected to structure. The rules for defining this space can be derived by creating a dialogue between 2-D elements, which play the role of partitions. An approach that is similar to the application of Eisenman's (1999) principles to a building designed by the Italian architect Giuseppe Terragni has been conducted by Ioan (2012) for the Romanian architect Marcel Iancu, as well as by Bostenaru Dan and Dill (2014). Bostenaru Dan and Dill (2014) looked for different methods of highlighting selected elements and their connections in an urban area, from visualising georeferenced photos and models to the configuration of the pedestrian routes among them according to landscape design. In the framework of this study, work has also been done on transposing this digital approach into the physical space in an exercise to determine visions and scenarios for new pedestrian streets along the N-S Magheru Boulevard. Summing up all of these approaches, the geometric approach of the diagram by Eisenman (1999) can be the basis for the geometrical modelling of language elements, such as those identified by Ioan (2012). At the urban scale, complex networks can be superposed to maps, thus having the mathematical vector dimension over the cartographical representation.

Because it is aimed at a multidisciplinary approach, an economic view is added to the way urban and structural/architectural building elements are mapped. In doing this, loss models were reviewed as an alternative to the statistical ones based on GIS analysis, namely, the structural mechanics models by Glaister and Pinho (2003) and Borzi et al. (2008); their models require the building scale to communicate with the urban scale based on the typologies in a method called displacement-based earthquake loss assessment (DBELA), in which the probability of failure is based on the resonance between vibrations, which depends on building height and structural element characteristics. From these studies, probabilistic analysis can extend the method up to urban loss estimation. These typologies build the landmarks/strategic elements in this study. The typological analysis of the landmark buildings is the basis for modelling modifiers, or macro-elements, taking into account the aforementioned morphogenesis. The macro-elements can thus approach the current or future changes in the structure of the building.

\section{Working principle and methodology}

The working principle in this paper is related to the goals of strategic planning. In urban planning, strategic planning means that the urban areas are not subjected to uniform treatment when urban regulations and the studies underlying them are made, as has been the practice, but rather, a hierarchy is established. Within strategic planning, the master plan is a vision which encompasses different planning levels and involved actors. The strategy does not become a regulation. The means to reach the planning goals are applied through measures packages at different planning levels and time horizons. At these levels (which correspond to different scales in GIS), action plans, which can be model plans, demonstrations and pilot plans are performed. These plans can assume different forms: a partial urban plan, a regulation for a limited area, an architecture project, a spatial structural concept, and/or a development scenario. The way they are performed can also vary (alternate projects, competitions, workshops), as can the means of participation (project team, leading group, private public partnership - PPP, in case of earthquake the Global Earthquake Model - round table, citizen and specialist forums) (Fassbinder, 1993). However, most important for the concept developed in this paper is that, instead of giving the same importance to all zones of the city - and editing them correspondingly - the planning strategy connects the intervention levels, one with another, and displays those intensive zones for which detailed solutions are determined, while other zones are described globally (Bostenaru Dan, 2004b). In order to apply the Lynch (1960) analysis at the vulnerable area of Bucharest, historic maps/plans are used as a basis, such as those in Lynch (1960), Sitte (1889) and Nolli (1748), which identify landmarks/strategic elements. Lynch's (1960) method identifies landmarks, paths, zones, boundaries, and nodes, as perceived by pedestrians who regularly walk in a specific city, i.e. according to the heritage habitat.

The RISK UE project (Mouroux and Le Brun, 2006) also identified strategic elements according to the disaster cycle phase. Such strategic elements support the decision 
system between actors at different levels. A grid is superposed on a map, as is done in planned cities or in computer games. This makes it easier to choose a typology which is common among other studied areas. As is the case in this study, these typological examples highlight landmarks in homogeneous urban areas. The landmarks are detailed using the macro-elements and the morphogenesis method. Reviewing the literature in the field, Romano (2014) for example has defined modifiers from a simplified structure for buildings in Italy that are contemporary with those on the Magheru (N-S) boulevard in Bucharest. In fact, Giovinazzi and Lagomarsino's (2004) method was derived from monumental structures (Lagomarsino, 1998), which can also build landmarks, and it has been employed in the RISK UE project.

At the building scale, structural morphology methods follow the rules of how forces are employed and tracked. Architects like Santiago Calatrava and Antoni Gaudi design their buildings to include a minimum of materials, following this (structural) morphological rule, while common buildings having rectangular shapes which hide the morphological shape. Ohmori et al. (2005) translated this approach to making retrofits by eliminating parts of structural walls until the edifice assumes an organic shape.

What plays a load bearing role at the building scale (like columns and beams seen as retrofit elements for the building typology in this study, corresponds to a strategic role at the urban scale. Strategic buildings, at the urban scale, are those which are used for emergency intervention and reconstruction, and hence, require a higher level of performance. Switching the load bearing - non-load bearing role corresponds to switching the function of a certain building. The paths connecting the buildings describe urban forces: the paths to be followed by agents in emergency interventions (Fiedrich, 2004) and also by citizens who are changing their residential or work locations according to the perceived disaster risk (Grinberger et al., 2014). An agent following movement is just a further development, which was intuitively well visualised by Debord (1957) in graphs: the representation of urban spaces either as fractals or as complex networks.

Between the two levels (building and urban), which are the pillars of the multiscale approach presented, lessons are learned through regression. By regression, in this context, it is meant that for data sets obtained from case studies, the hypothesis for the decision tree is induced. From these individual hypotheses, a single hypothesis is obtained, to be integrated into the guidance. The hypotheses for the individual elements are then derived, and finally, statements about them are deduced. These statements are used as feedback to compare with the induced hypothesis in order to regressively reformulate the latter. The flow of forces at the urban level becomes the flow of agents in an intervention at different stages in the disaster cycle (ex. crisis or reconstruction). While such agents can also be simulated in GIS or in computer games, at this stage of the research, a software like Adobe Director was used for visualisation, which is also the basis for representa- tion software that include zooms, such as Prezi software. The software allows the movement of images, and the inclusion of real time 3-D, as well as the creation of the superposition of elements from different time spans.

In Fig. 1 there is the general workflow of the methodology. The first two tasks of the methodological steps are directly derived from the Lynch (1960) approach (Fig. 1). Task 3 is a consequence of applying the concept of the grid in planning, while Task 4 builds on 3 and 2 and will be the subject of further research papers. The component of digital humanities (digital methods for cultural heritage) is especially strong in the first two tasks.

\section{Applications}

\subsection{The zoom level of the building}

At the building level, the study area is a central protected zone in Bucharest, located north of the historic centre: the Magheru Boulevard. Typologically, it has the highest frequency of buildings which are classified, according to earthquake engineering expertise, in risk category $\mathrm{I}$, but at the same time, constitutes a unique cityscape in Europe. The uniqueness consists in having such a high number of buildings from the 1930s as the building fronts, instead of just having empty plots throughout the city, as in other locations. The 1977 earthquake damaged numerous buildings, some of which collapsed, and were altered or replaced; hence, the original unity is no longer present. In Fig. 2 is the location of Magheru Boulevard in the city.

A first step in the workflow was to create a database to be used in further investigation. At the building level, archival images of plans were examined to establish a typical floor plan which can be considered as characteristic of the zone, and at the same time, has the unique characteristics of the landmarks that will be used in morphogenesis. The source of the archival data in this study is the records in Bucharest City Hall. Magheru Boulevard was built around the 3rd decade of the 20th century, and thus, the building plans have been conserved. The building plans, however, rarely contain details regarding structure. Archival images can be placed in dialogue with building surveys, as alternatives to gather the existent structure - the different methods lead to different classifications. For example, building survey photographs can provide details regarding the uncovered structural elements.

After consulting the relevant archival images, the next step was the determination of the respective risk class (Fig. 3) or the ones displaying high architectural value. According to a study of the URBASRISK (2015) project, in prioritising decisions in interventions to mitigate seismic hazard, two contradictory factors are important: seismic vulnerability and cultural values. The extent of an intervention is greater for the first and less for the second of these factors. The architectural value was not mapped in the GIS database to which access 


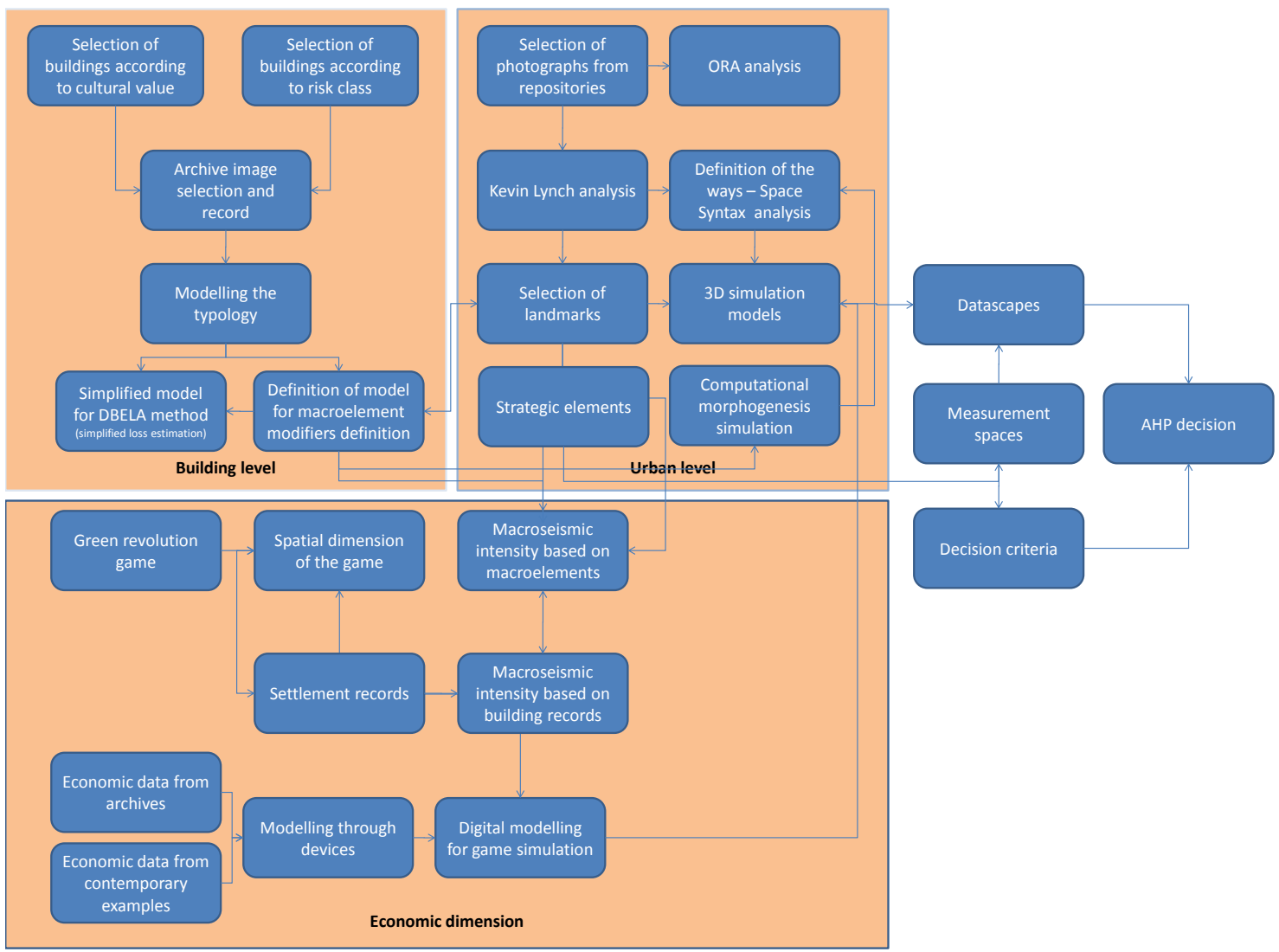

Figure 1. Methodology workflow with emphasis on those detailed in this paper.

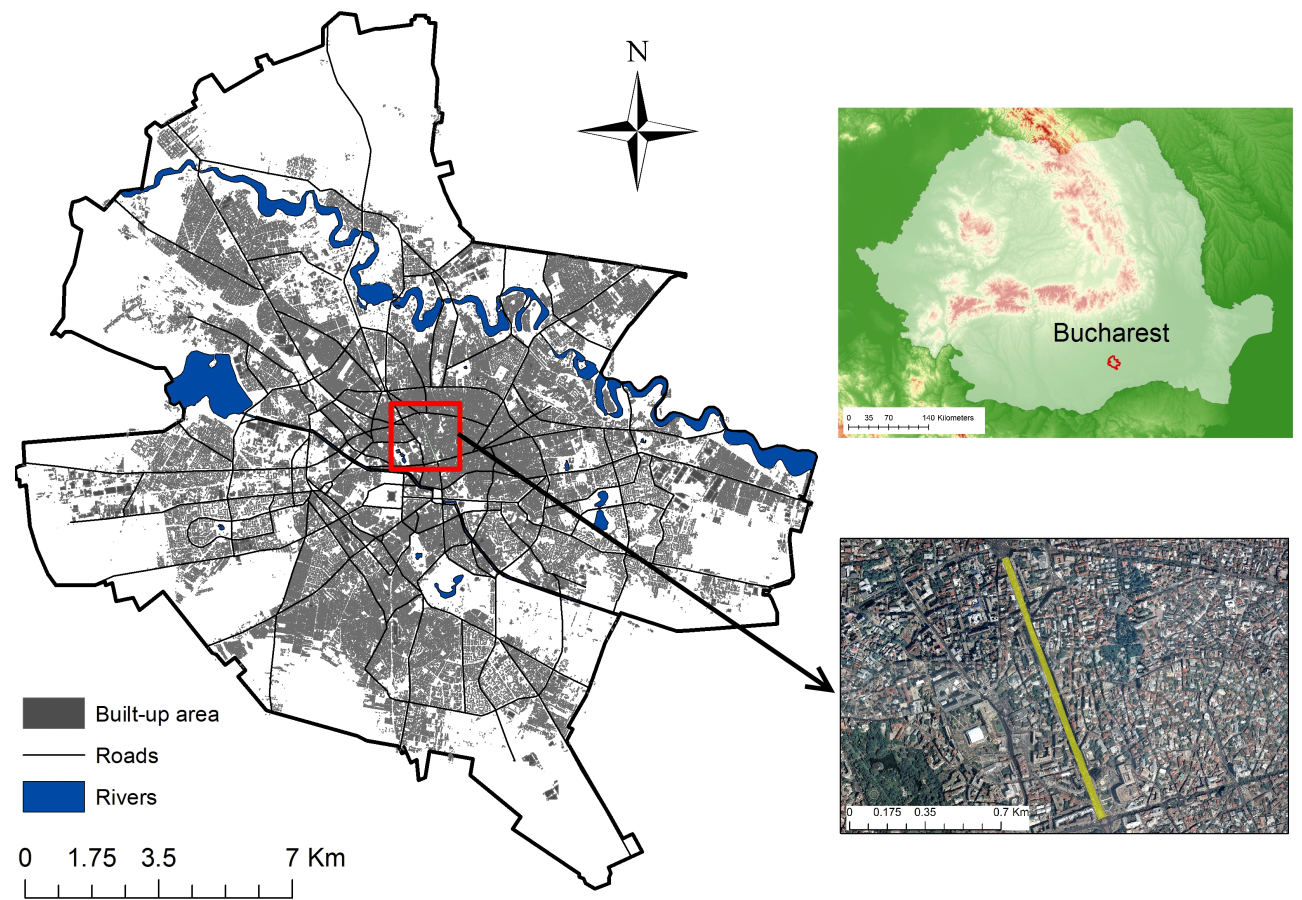

Figure 2. Position of the Magheru Boulevard, which is located in the northern part of the historic centre of Bucharest. 


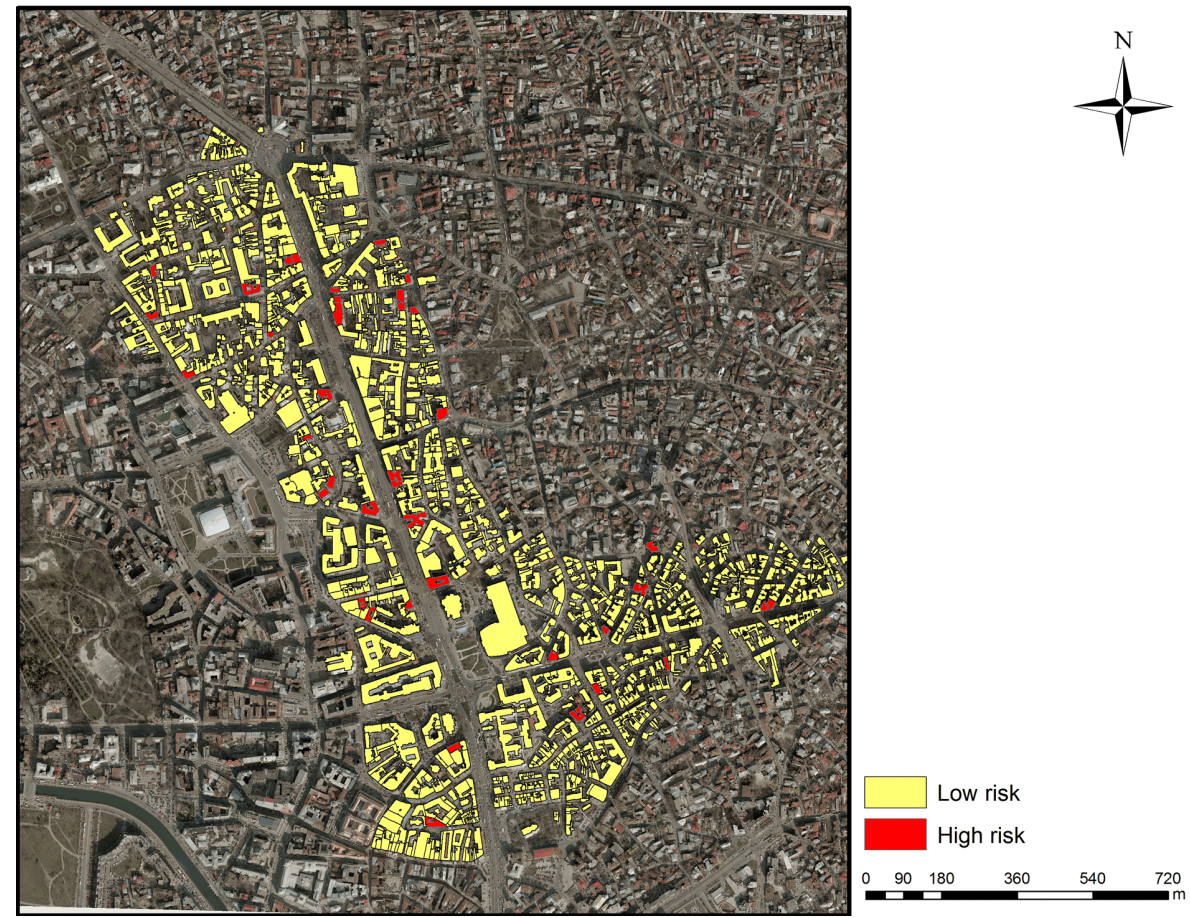

Figure 3. The N-S (Magheru) boulevard area, highlighting the risk class I buildings.

was granted, so the plans for the protected zones of Bucharest and the monument records were consulted. In this area, several levels for the protection of buildings were identified: individual monuments, collective monuments, protected assemblies, and protected zones. Urban routes between such elements can be identified, as shown in Bostenaru Dan and Dill (2014).

These geometric elements can form a catalogue for digital modelling (GDL), for a library of elements in CAD, and thus, for a more rapid modelling of prototypes for 3-D modelling of urban areas. In this research, it has been attempted to identify these kinds of modifiers between the structural dimension and the architectural dimension of morphology. In this way, the relationship between space and structure is highlighted. The structural dimension of morphology determines the structure as a load bearing scaffold on which the architectural space, both as an atmosphere and as a container for a function, is shaped. The way in which it is shaped is defined by the architectural dimension of morphology. For computational morphogenesis, a grid is considered as a basis on which both morphologies are pinned. This will also be helpful in the later loss computations, for which building elements (like those composing the macro-elements) are considered from the level of a survey on which the architectural morphology is based.

Once the plans of the characteristic buildings from the archive were obtained, a typological study was performed in order to establish the model for computational mechanicsbased studies of vulnerability (Borzi et al., 2008; Glaister and
Pinho, 2003). The possible structure of the buildings as reinforced concrete skeleton buildings was simulated (Fig. 4).

A model resulting from these studies can be more detailed in terms of complexity, as was the one that was included in the World Housing Encyclopedia description (Fig. 5). Such a model can be used for finite element model simulations, as is necessary for the macro-element method of Giovinazzi and Lagomarsino (2004). Pursuant to this method, which is fully coherent with the approach in this paper, landmarks are chosen for detailed modelling, in order to draw conclusions regarding urban zones. The model in Fig. 5 is detailed enough to allow the identification of modifiers, as in the macro-elements method, i.e. the removal of some details through simplification, resulting in a simple model, such as that shown in Fig. 4.

\subsection{The zoom level of the urban area}

At the urban scale, the typology leads to simplified models, as considered in the economic and decisional approach (Bostenaru Dan, 2004a). A prioritisation of different interventions for buildings of the same typology, and not a prioritisation among heterogeneous buildings in the same urban area, could be done. For a prioritisation of buildings, Glaister and Pinho's (2003) method can be employed. At its basis, the simplified methods from the typology are necessary, because the method computes building failure based on the characteristics of columns, spans between successive columns, heights, and the expected earthquake. After run- 

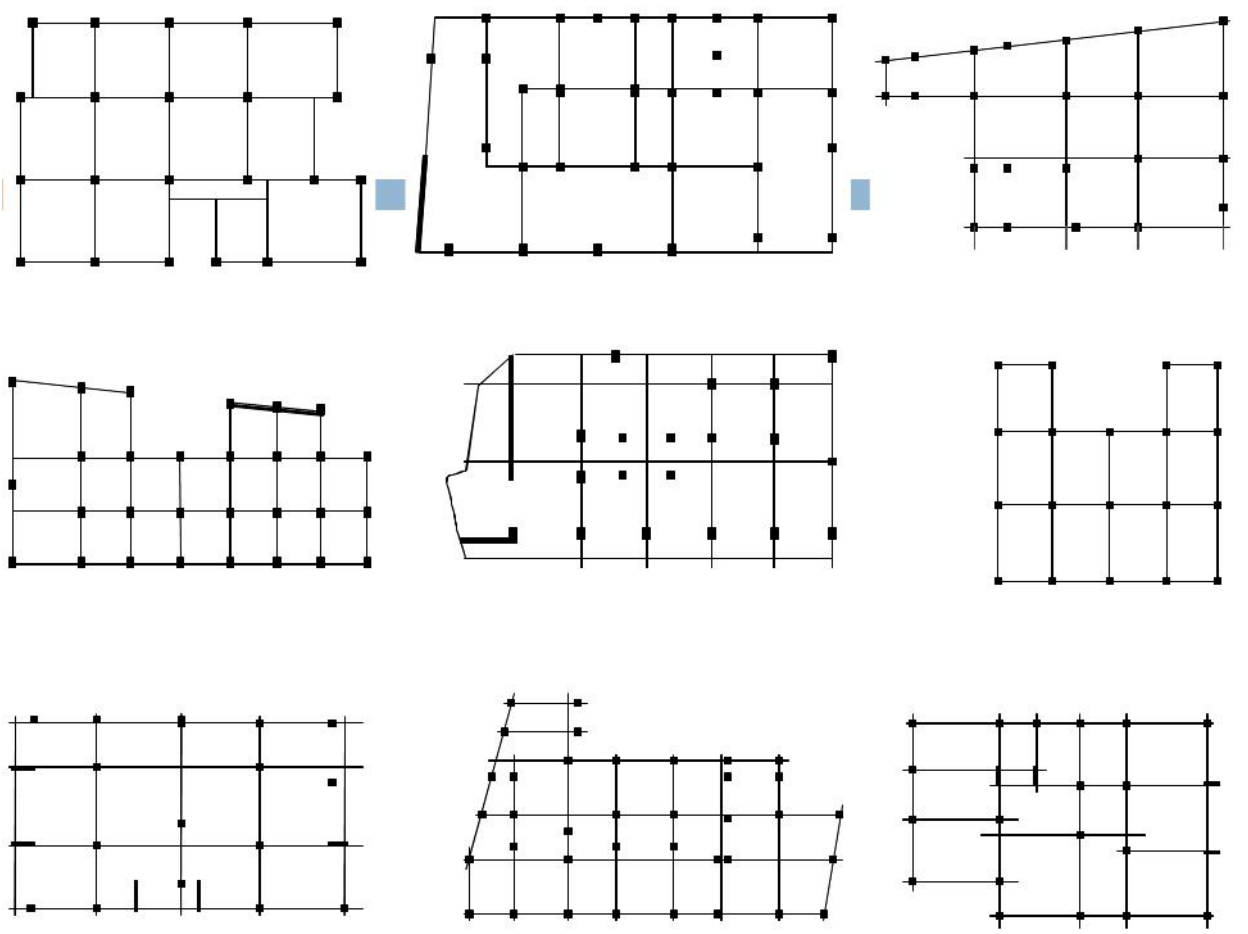

Figure 4. Typological studies.

ArchiCAD STUDENTEN-Version. Wueterverkauf oder kommerzieller Ensatz nicht enlaubt.

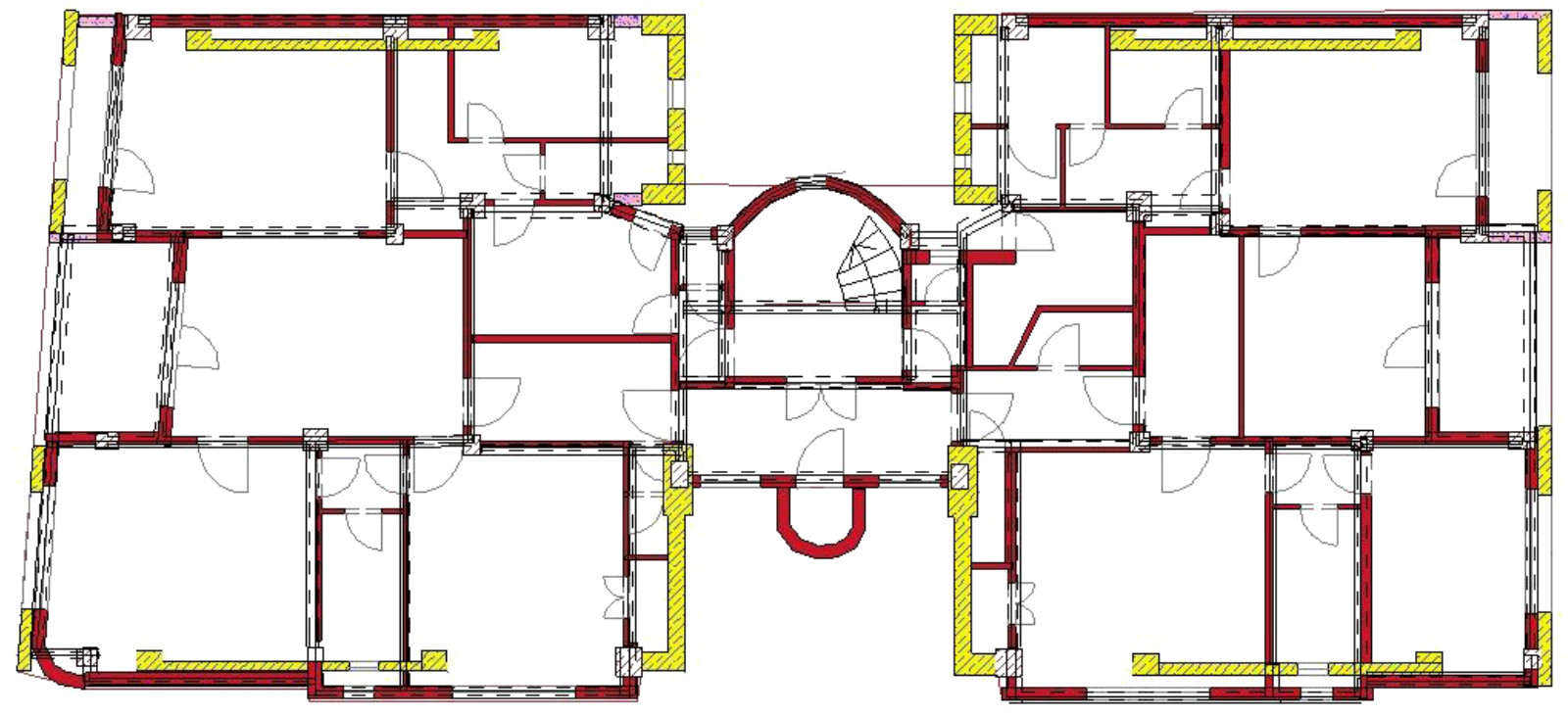

GRAPHISOFT

Figure 5. Model of Romanian interwar building in the World Housing Encyclopedia. 
ning this computation, it was obtained that building class over 4 stories proves to be the most vulnerable in Vrancea earthquakes. This modelling is suitable for the area, but not for the landmark.

\subsection{The zoom level of the urban zone}

At the urban level, the archival image is that of 19th20th century photography, in combination with various urban 3-D representation methods (GIS, Google Earth, SELENA, fractals, the urban routes game proposed by the authors, SemCity, Second Life). The latter are investigated based on a questionnaire developed in TU0801 COST Action, as depicted by Bostenaru Dan and Panagopoulos (2014). This approach builds on a Lynch (1960) analysis of the Magheru Boulevard in Bucharest, which encompasses the design of the pedestrian routes. On the other hand, Popa (2014) performed for the same area an analysis of landscape photography for the agricultural landscape in accordance with Lynch's (1960) principles. Tension lines or other characteristics of the landscape are identified by Lynch (1960) as some of the elements in the definition of perception: node, landmark, zone, boundary, and path (names given by Lynch to the elements of the image of the city).

Tension lines are lines which order landscape elements in visual perception. They may be roads, or the boundary of a forest, or a mountain line. In a city they may be the flow of cornices, or tree alignments. Unlike tension lines, the denominations by Lynch (1960) refer to identification of elements on a map and not in a photographic or drawn image. Hence, they are more important for the scope of the paper, which relates to mapping. However, a number of images from the Canadian Centre for Architecture depicting ruins after disasters are available. These images are photographs, mostly from 19th century disasters, including also earthquakes such as San Francisco 1906. Lynch's (1960) elements can be recognized on these images for example using tension lines to recognize a node or a boundary. Again, more tension lines delineate a zone. At the intersection of tension lines are nodes. Tension lines are at the same time geographic elements which can be used in geocoding. For Bucharest, historic images are available for the central area, as well.

In this research, images of disasters (such as those in Kozák and Cermák, 2010 and Wieczorek et al., 2014) are considered, to which this methodology can be applied. The Lynch analysis gives the correspondence between the two scales. The 19th century photography of Bucharest was obtained from the archives of the library of the Academy in Bucharest, while 19th century photography of disasters worldwide is available in the 2010 research of the first author at the Canadian Centre for Architecture in Montreal.

The images are investigated according to the Popa (2014) method, which is based on Lynch, and it is placed in the context of complex networks with the images of other disasters.
The software ORA allows for typological, but not for spatial connections (Fig. 6).

In this research, the quantitative aspects are essential. As such, an ontology to organise the consulted database was worked out, in dialogue with other databases. Parameters connected to photography which could be used to organise the information and lead to a computerised catalogue of new elements were defined. The concept of the database has been published in Bostenaru Dan (2011). The diagram in Fig. 6 shows the results as presented at the Future of Historical Network Research conference (HNR, 2013). The data connected to each photograph, as included in the ontology for the database, are transformed in metadata and lead to a network in which similar features are connected through the ORA software. This software is not as connected to sequential connections as other softwares, but instead, it groups the types of criteria which connect the different images.

The software proposed to be employed and the method of Eisenman (1999) allow superposition on the map and zooming from the cartographic elements to the photographic elements. In a classical GIS environment, the link between the geographic location and the images for the Magheru Boulevard has been established by the first author within the framework of the SFB 461 project Strong Earthquakes (Sonderforschungsbereich 461, 2008) at the University of Karlsruhe.

The connection between the building level and the urban level identified landmarks is specifically provided by the definition of macro-elements. As Lagomarsino (1998) shows, macro-elements define the level of damage according to how much they suffer in earthquakes. This means that a certain damage pattern is typical for a modifier that is identified in the model. Such damage patterns can be taken from descriptive archival records, as in the history (of art), but also from reconnaissance photographs. Certain types of damage have a certain 3-D display as well, as discussed by Schweier et al. (2004). In a continuation of that previous work, Schweier and Markus (2006) produced 3-D models of typical buildings in order to help assess the damages at the urban scale. The CAD models are those of the landmark and of the typological model at the building scale, which can be identified in the urban scale images. For landmarks, the comparison between the aerial image and the eye level view is important. An example of a modifier, according to Lagomarsino's (1998) macro-element model, for buildings from the mid-20th century on the Magheru Boulevard, is the pancake collapse of the Wilson block tower (Fig. 7). A pancake collapse, and how it can be recognised in photographic images, is included in the Schweier et al. (2004) catalogue. The towers of mid-20th century buildings have been discussed by Romano (2014).

The analyses of satellite images and artistic images from the aforementioned archives are complementary work.

Work with the images is done from multiple points of view. The completed research includes the philosophical un- 
Catastrophe Photography
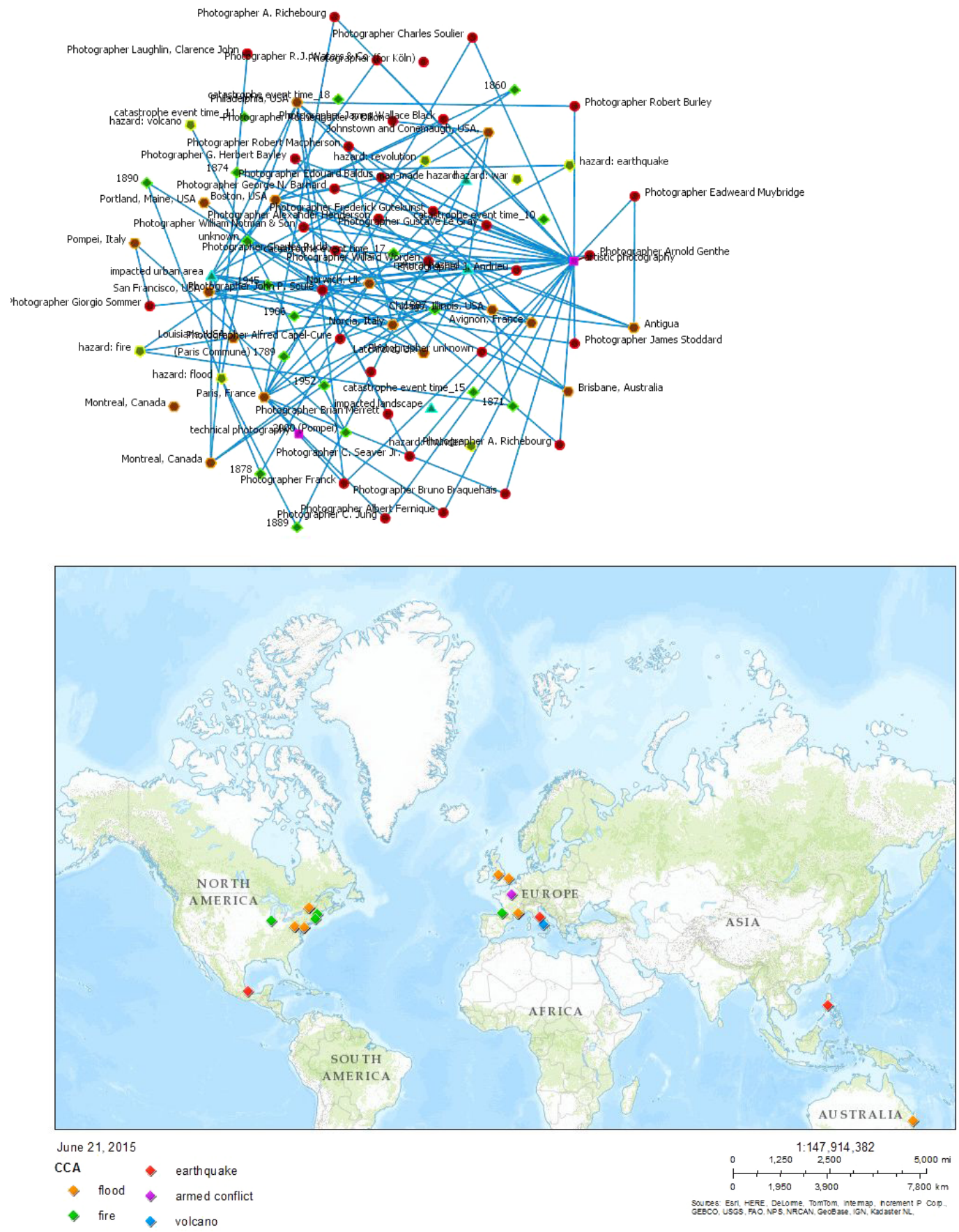

Figure 6. Historical network research of catastrophe photography. Above: the network method we propose applied for the locations on the bottom using an ontology of data connected to the images.

derstanding of photography and representation quality, including memories, as represented by ruins (De Meyer, 2011).

So far, the historic events from the Canadian Centre for Architecture archive have been considered, which are mainly historic events that occurred in the 19th century. An incidents database could be built and mapped in a different way. More traditional ways of mapping, which are less connected as a database, but which have a stronger spatial dimension, were employed by the DESURBS project (DSSP, 2015; CIMNE, 2015). These were used to map contemporary (past 20 years) 


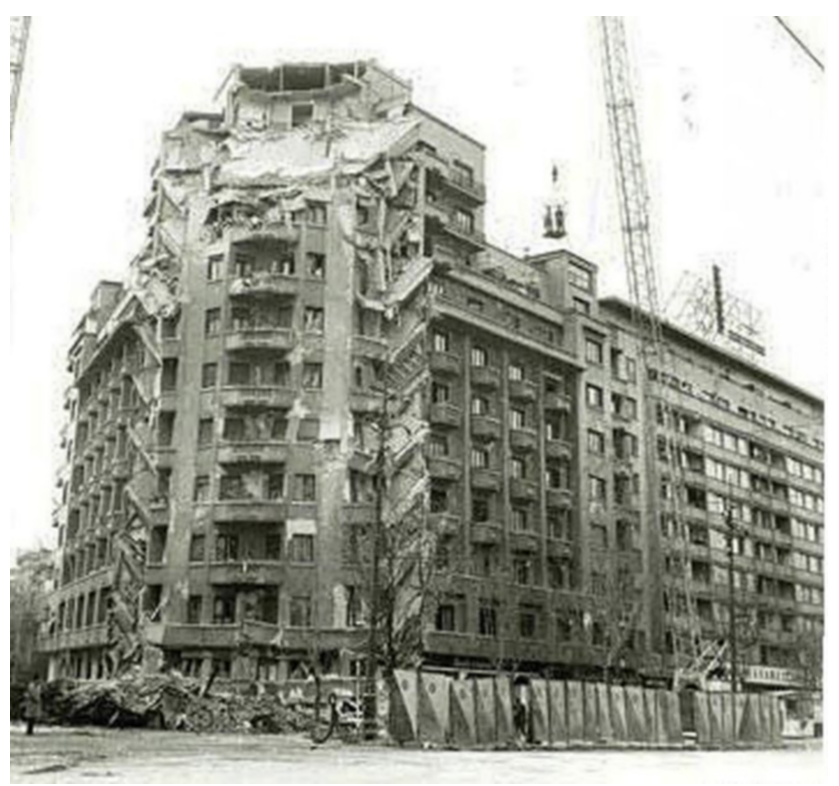

Figure 7. Wilson block of flats after earthquake (1977). Source: courtesy of Rezistenţa urbană (Urban resistance).

events. If they are mapped in a unitary way, both databases can represent different slices of time. Apart from these two databases, a number of other incident data could be mapped this way. These include major historic incidents, many of which preceded the era of photography. The book by Kozák and Cermák (2010) on the illustrated history of natural disasters is one source of data, while the book by Wiczorek et al. (2014), which provides a catalogue emerging from a project and exhibition on Images of Disasters, is another. Finally, within the coursework supervised by the first author and Gociman, further data on historic, but more recent, incidents were collected, and could be used to update the DESURBS database. Unlike the DESURBS approach, which looked for weak points to be avoided using the developed tools, the focus in this paper is on the visual representation of the impact, i.e. on the image.

Applying the same method from these lessons learned for macro-elements, special ontologies for buildings (English heritage, 2015, architectural elements ontology from the University of Geneva - presentation in frame of the SemCity project by Gilles Falquet, not accessible anymore; Getty, 2015) were consulted.

For the city level, as a task to be developed in the future, the relationship between the urban morphology and the constructive structure is considered. Depending on whether the city was shaped by organic growth or planned, between tradition and innovation, the shape can be organic or superposed to a grid. Although the approach described here is to underpin a grid to the developments caused by the impact of disasters to obtain better visualisation, sometimes this can be seen in the development of the street network - along
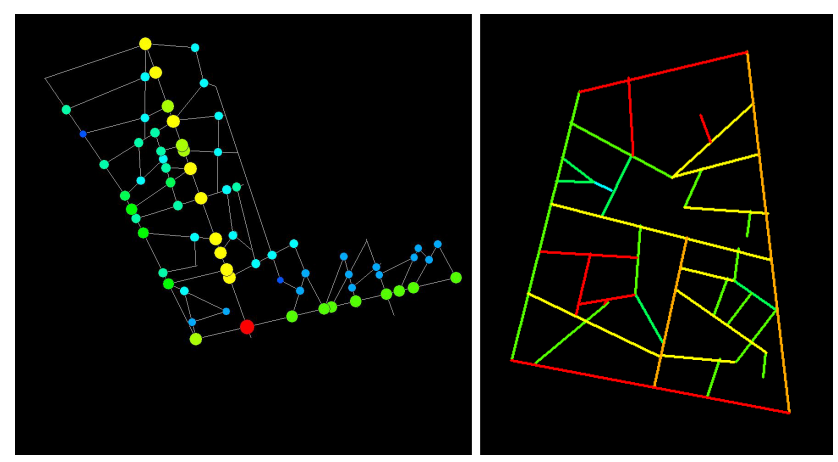

Figure 8. Space Syntax analysis of the street network in an organic (historic centre) and a pre-planned (Magheru Boulevard) area, following two modes of expression.

which the paths are constructed and along which the agents move. It was investigated in particular the street network of the Magheru Boulevard area in the centre of Bucharest. A Space Syntax analysis was chosen as a complex network and graph investigation means. Figure 8 displays the nodes from a Lynch analysis considering the accessibility of landmarks.

Morphologic decomposition is followed by the classification of the elements, which is based on the documentation made in the previous task. In this Space Syntax analysis, the graph of the network is cartographically superposed. A combination of the two methods can lead to the mapping of the images of disasters. Either artistic or technical images can be mapped in a place which is adequate as a landmark or node. The aim for this approach is the optimisation through element reordering, based on the strategic role of the different elements. Deleuze (1980) differentiates between smooth and striated spaces. Deleuze (1980) uses several metaphors to exemplify this: the nomad and the sedentary, the textile metaphor (felt and woven) etc. A metaphor can be created along these lines for reconstruction. Sometimes in reconstruction a different pattern is used than before reconstruction. A well-known example is Lisbon 1755 when instead of the Middle Ages street pattern, the Baixa was created, with rectangular streets. This is a place where the non-fractal replaced the fractal structure of the urban tissue. A counterexample is London after the 1666 fire, where the old street pattern had been kept. Also other reconstructions considered smoothing and striation, such as Le Corbusier's plan for Paris. In case of Bucharest, articles in the journal Arhitectura from the 1940s (Cerkez, 1940), after the major earthquake struck, consider that the collapse of some buildings should have been occasion for restructuration by creating, for example, more green spaces. Also, the Bucharest historic centre was reshaped following the 1847 fire, with a new street grid, which is superposed on some of the old buildings (ancient hotels). The foundation of it has been recovered in recent restructuration efforts. Recovering the images of lost buildings and public spaces of the city on maps would be another 
level of the application of the Bostenaru Dan and Panagopoulos (2014) method. The role of green has to be considered, as well as the memory of the ruins, for example, the lost gardens. The method described here is another level of the fractal connection between the part and the whole, as the loss models and the urban routes. Urban routes serve to transpose the digital routes into physical space, as their implementation requires scenarios and strategic planning.

\section{Discussion and conclusions}

In this research also the relationship between the information from the archives, which were collected for this study, as well as the information from the building survey in the field (physical dimension) for the decision-making process in earthquake risk mitigation were investigated. The information from the archives includes the drawings of plans, which can be used to generate ontologies, making it possible to define macro-elements and taking the interior of the building, in its entire 3-D dimension, into consideration. The differences between the two approaches are found in their attempts to adapt methods for new buildings in the approach to historical buildings. For several decades, different methods have been concerned with this goal, but there has been no unanimously accepted solution. Macro-elements do not have to be defined as the changes in the simplified structure, as seen in Romano (2014); they also consider the earthquake damages, depending on what stopped working and what can be identified as patterns in the urban images of destruction (see the catalogue in Schweier and Markus, 2006). Such macro-elements can be elements in the 3-D library (for ex. how does ArchiCAD complete the library with elements, as there is such an element for green walls) and can be used again at other sites, as well as for structural software (ex. SeismoSoft). ArchiCAD also has the advantage, for the developed concept, of being able to make a plan part of another plan, for example, part of the urban plan. These plans are defined through the geometric modelling language. For this reason, also the references of the diagram (Eisenman, 1999) were consulted to see how the geometry is reflected. Ionescu (2011) saw the diagram as being the expression of a catastrophe as a pictorial representation. However, the diagram can be also looked at as an expression of temporality, as related to photographic rendering. Geometry can also be combined with augmented reality, as Markus and Schweier's (2006) study showed. This way, another link between the physical dimension and the digital dimension is created, in addition to the field data collection and the scenario development for pedestrian routes. Furthermore, the search direction of the relationship between the geographic scales, for which details with the macroelements are provided, is confirmed. The zoom generated by the detailed treatment of some strategic zones makes the applications more economically feasible. The zoom can also be adequate for different associated cultural values (protected zones, assemblies with ambient value, historical buildings, etc.), because the zone considered in this detailed study is protected.

The developed ontology for photography can also be applied to search for 3-D models that have already been constructed for import into the developed application. The macro-elements method is also useful for the 3-D modelling of buildings as cultural heritage: modules like the modifiers can be marked and identified for 3-D searches, or they can be defined as templates for future 3-D reconstructions, through the geometric modelling language. With this goal, the virtual library EUROPEANA (2015) was approached (to see the metadata, and models of Romanian buildings will be contributed as a start. Figure 5 is just one of the models covering the whole span of Romanian historical buildings modelled in 3 -D which can contribute to EUROPEANA. The addition of metadata will enhance the possibility that these buildings can be mapped at other geographical scales and in different complex networks. The parametrical study for these models does not have to consider a mesh for their modelling, but rather, macro-elements, based either on structure or on the architectural style. These metadata can be compared with these study parameters. This is an example of the lessons learned regarding the two scales that are addressed in this paper.

Van Oosterom and Stoter (2010) developed the concept of 5-D modelling, which means $3-\mathrm{D}+$ time + scale. The underlying idea is the same, namely to save resources from the detailed modelling in 3-D of whole areas, so that certain areas are presented in more detail (the scale dimension). In the approach in this paper, however, which depicts the urban studies dimension, instead of the computer science dimension, with an emphasis on the humanities, it is also innovative that the specific ingredients for modelling natural hazards have been considered, with detailed areas being defined as strategic elements for risk mitigation.

Another progressive idea is the so-called "time machine". A multimedia application for the city of Köln was developed, in which there is a time slide; however, these transformations have to be visible in a graphic way, on the map or in a 3-D model. The macro-element modifiers can precisely mark this change in time. The models obtained through morphogenesis can be printed in 3-D. If going into the study of iconography, this modification in time can be shown through graphical codes (colour, transparency). In Schwäbisch Hall (Germany), a project has been done (Schwäbisch Hall, 2015) in which the archive plans have been considered for a lexicon of houses. The city has to be seen as a network of the stories of houses, which is strongly connected with social stories, as in building archaeology. "Paths" from The Image of the City by Lynch (1960) act as hyperlinks between these stories (between the house correspondent of these stories); the city is a network in this sense, which can be represented digitally, as a space syntax, or physically (see the AESOP, 2015). The "path" becomes a story, and this way, the means of social sciences and humanities (narratives) are imported into this 
research. The nodes can be a course in space and time. The creation of such a path can occur in the virtual space (as for the lost landmarks in Köln, Lisbon or Bucharest) or in real space. To create such a route, new curators are needed. For the investigation of such networks, complex networks can be used (the graphs between images, ex. COMOB, see Amoroso et al., 2013), but also, the proposed ORA grouping can be used. In the ORA grouping, metadata are considered, but also the object itself (the analysed image) and the narrative text. How to superpose the complex network to the geographical dimension, the map remains a further challenge.

\section{Outlook}

In the framework of the presented methodology, it is aimed to integrate the findings of the study in a decision system based on a regression between the two scales. From game theory, a next step can be taken to drama theory (employing conflict manager software) and to analytic hierarchy in decisions, instead of a decision tree. This way, the qualitative aspect precedes the quantitative. However, it is necessary to take into account that, while GIS considers the qualitative aspects, datascapes are built on quantitative aspects. Datascapes are 3-D models of GIS plotted into Google Earth, where the height dimension is replaced by plotting data connected to different characteristics of the building. In an attempt to consider both, the qualitative aspects from GIS are translated for datascapes, based on their agent-based modelling role - the landmarks and strategic elements serve a certain area of a residential zone, for example. From the measurement spaces employed for the criteria at the building level, it is thus went to the measurement spaces for the urban datascapes through regression. In a first step at the urban level, weights were assigned to the GIS, but this will be the subject of another article. These criteria can be connected through an ontology or through a complex network for translation into an exploitable foreground for a computer system. In this paper, focus was on the necessity to zoom at the building level by not considering it only as a statistics item, as is usually with GIS-based methods, but visualising it in both the structural assessment (the macro-elements method) and in the images of disasters (through perception). This is possible using the other tools mentioned in the paper.

Acknowledgements. This work was supported by the strategic grant POSDRU/159/1.5/S/133391, Project "Doctoral and Post-doctoral programs of excellence for highly qualified human resources training for research in the field of Life sciences, Environment and Earth Science" co-financed by the European Social Found within the Sectorial Operational Program Human Resources Development 2007-2013".

Edited by: M. Parise

Reviewed by: M.-A. Anghelache and three anonymous referees

\section{References}

AESOP - The Association of European Schools of Planning: The Thematic Group "Public Spaces and Urban Cultures", June 2014 Bucharest, Romania, http://becominglocalbucharest.ro/, last access: October 2015.

Alexander, C., Ishikawa, S., and Silverstein, M.: A Pattern Language: Towns, Buildings, Construction, Oxford University Press, 1977.

Amoroso, N., Hudson-Smith, A., Phillips, M., Speed, C., and Willis, K.: Concept for workshop: Patch-Scape - Pads, Pods, Phones and Spatial Data, in: Peer reviewed proceedings of Dig-5 ital Landscape Architecture 2013 at Anhalt University of Applied Sciences, edited by: Buhmann, E., Ervin, S. M., and Pietsch, M., Wichmann, Berlin, 330-341, 2013.

Bassett, K.: Walking as an Aesthetic Practice and a Critical Tool: Some Psychogeographic Experiments, J. Geogr. High. Educ., 28, 397-410, 2004.

Bögle, A.: Zur Morphologie komplexer Formen in Bauwesen, doctorate thesis, Universität Stuttgart, Stuttgart, 2004.

Borzi, B., Crowley, H., and Pinho, R.: Simplified Pushover-Based Earthquake Loss Assessment (SP-BELA) Method for Masonry Buildings, Int. J. Arch. Herit., 2, 353-376, 2008.

Bostenaru Dan, M. D.: Multi-criteria decision model for retrofitting existing buildings, Nat. Hazards Earth Syst. Sci., 4, 485-499, doi:10.5194/nhess-4-485-2004, 2004a.

Bostenaru Dan, M.: "Economic Efficiency and Applicability of Strengthening Measures on Buildings for Seismic Retrofit. An action guide", International Conference "Disasters and Society From Hazard Assessment to Risk Reduction”, 26-27 July 2004, Karlsruhe, Germany, in: Disasters and Society - From Hazard Assessment to Risk Reduction, edited by: Malzahln, D. and Plapp, T., Logos Verlag, Berlin, 289-296, 2004b.

Bostenaru Dan, M.: Multidisciplinary co-operation in building design according to urbanistic zoning and seismic microzonation, Nat. Hazards Earth Syst. Sci., 5, 397-411, doi:10.5194/nhess-5397-2005, 2005.

Bostenaru Dan, M.: The use of ontology for digital conservation of architecture works after catastrophes, J. Appl. Eng. Sci., 1, 1118, 2011.

Bostenaru Dan, M.: Aspects of Architecture and Urbanism in the Reconstruction of Disaster: Comparison of L' Aquila (Italy) with Kolontar/Devecser (Hungary) and Corbeni (Romania) in the Context of Participative Reconstruction, in: Earthquake Hazard Impact and Urban Planning, edited by: Bostenaru Dan, M., Armas, I., and Goretti, A., Springer, Dordrecht, 259-291, 2014.

Bostenaru Dan, M. and Dill, A.: Spatial Street Network and Urban Routes Around the Modernist Boulevard in Bucharest, in: Planning and Designing Sustainable and Resilient Landscapes, edited by: Crăciun, C. and Bostenaru Dan, M., Springer Netherlands, Dordrecht, 187-217, 2014.

Bostenaru Dan, M. and Panagopoulos, T.: Digital representation of the impact of the 1755 Lisbon earthquake, Editura Universitara - Ion Mincu, Bucharest, 2014.

Bridger, A. J.: Visualising Manchester: Exploring New Ways to Study Urban Environments with Reference to Situationist Theory, the Dérive, and Qualitative Research, Qual. Res. Psychol. 11, 78-97, 2014.

Cerkez, A.: După cutremur, Arhitectura VI, 3-4, 15-16, 1940. 
Chirvasie, C.: Oraşul - sistem cibernetic - fuzzy - frahtal, Postgraduate thesis, "Ion Mincu" University of Architecture and Urbanism, Bucharest, 1995.

CIMNE: International Center for Numerical Methods in Engineering database developed for the DESURBS project, http://www2. cimne.com/websmaps/desurbs/mapa.aspx, last access: $31 \mathrm{Au}-$ gust 2015 .

Darby, K.: Framing the Drift and Drifting the Frame: Walking with Wrights \& Sites, New Theatre Quart., 29, 48-60, 2013.

Debord, G.: Introduction to a critique of urban geography, in: Situationist International Anthology, edited by: Knabb, K., Bureau of Public Services, Berkeley, CA, 5-8, 1955.

Debord, G.: Naked city map, http://paavo.tumblr.com/post/ 3583109092 (last access: 9 October 2015), 1957.

Deleuze, G.: Mille Plateaux, Minuit, Paris, 592-625, 1980.

De Meyer, D.: Catastrophe and its Fallout - Notes on Cataclysms, Art and Aestetics, 1755-1945, in: Tickle your catastrophe!, studies in performing arts \& media \#9, edited by: Le Roy, F., Wynants, N., Hoens, D., and Van der Beeken, R., Academia Press, Gent, 13-32, 2011.

de Souza e Silva, A. and Hjorth, L.: Playful Urban Spaces. A Historical Approach to Mobile Games, Simul. Gaming, 40, 602-625, 2009.

DESURBS: Designing Safer Urban Spaces http://desurbs.eu/, last access: 31 August 2015.

DSSP: Decision Support System Portal fort he DESURBS project, http://desurbs.it-innovation.soton.ac.uk/, last access: 18 September 2015.

Eisenman, P.: Diagram diaries, Thames \& Hudson, London, 1999.

English heritage: Forum on Information Standards in Heritage (FISH) Thesauri, http://thesaurus.historicengland.org.uk/, last access: 21 September 2015.

EUROPEANA: Virtual library Europeana, http://www.europeana. eu/portal/, last access: 31 August 2015.

Fassbinder, H.: Zum Begriff der Strategischen Planing, in: Neue Wege in der Planungskultur. Orientierungen in der Zeit des Umbruchs, edited by: Brecht, J., VWP - Verl. für Wiss. Publ., Darmstadt, 323-326, 1993.

FEMA: Rapid Visual Screening of Buildings for Potential Seismic Hazards: A Handbook, 3rd Edn. (first edition was 1988), FEMA P-154, available at: http://www.fema.gov/media-library-data/ 1426210695633-d9a280e72b32872161efab26a602283b/

FEMAP-154_508.pdf, last access: 1 January 2015.

Fiedrich, F.: An HLA-Based Multiagent System for Optimized Resource Allocation After Strong Earthquakes, Doctorate thesis, University of Karlsruhe, Karlsruhe, Germany, 2004.

Florescu, T.: Formă şi transformare urbană, Editura Universitară "Ion Mincu", Bucharest, 2009.

Getty: Getty Vocabularies, http://www.getty.edu/research/tools/ vocabularies/, last access: 21 September 2015.

Giovinazzi, S. and Lagomarsino, S.: A macroseismic method for the vulnerability assessment of buildings, Paper No. 896, 13th World Conference on Earthquake Engineering, 1-6 August 2004, Vancouver, B.C., Canada, 2004.

Glaister, S. and Pinho, R.: Period-height relationship for existing european reinforced concrete buildings, J. Earthq. Eng., 7, 107140, 2003.
Gociman, C. O.: Managementul reducerii riscului la dezastre: strategii de arhitectură şi urbanism, Editura Universitară "Ion Mincu”, Bucharest, 2006.

Grinberger, A. Y., Lichter, M., and Felsenstein, D.: Dynamic Agent Based Simulation of an Urban Disaster Using Synthetic Big Data, working paper, http://pluto.huji.ac.il/ msdfels/ wpapers.htm (last access: 28 February 2015), 2014.

Harley, J. B.: Deconstructing the map, Cartographica: The International J. Geogr. Inform. Geovisual., 26, 1-20, 1989.

HNR: 13-15 September 2013, Hamburg, Germany, http://historicalnetworkresearch.org/hnr-events/ the-future-of-hnr-conference-13/ (last access: 31 August 2015), 2013.

Ioan, A.: Marcel Iancu şi alfabetul său formal: un exerciţiu didactic în derulare (I), Arhitectura, 3, 22-39, 2012.

Ionescu, V.: It is as if ... a catastrophe overcame the canvas" Deleuze and the pictorial set-up, in: Tickle your catastrophe, edited by: Le Roy, F., Wynants, N., Hoens, D., and Vanderbeeken, R., Academia Press, Gent, 111-118, 2011.

Kahn, H.: Thinking about the unthinkable, Avon, New York, 1962.

Kozák, J. and Cermák, V.: The Illustrated History of Natural Disasters, Springer Netherlands, Dordrecht, 2010.

Lagomarsino, S.: A new methodology for the post-earthquake investigation of ancient churches, 11th European Conference on Earthquake Engineering, Balkema, Rotterdam, 1998.

Lynch, K.: The image of the city, MIT Press, Cambridge, MA, 1960.

Mouroux, P. and Le Brun, B.: Risk-UE project: an advanced approach to earthquake risk scenarios with application to different European towns, in: Assessing and Managing Earthquake Risk, edited by: Sousa Oliveira, C., Roca, A., and Goula, G., Springer, Dordrecht, Geotech. Geol. Earthq. Eng., 2, 479-508, 2006.

Nolli: Plan of Rome by Nolli, digitised at: http://nolli.uoregon.edu/ (last access: 29 August 2015), 1748.

Ohmori, H., Futai, H., Iijima, T., Mutoh, A., and Hasegwa, Y.: Computational Morphogenesis and its Application to Structural Design, Proceedings of International Symposium on Shell and Spatial Structures, Bucharest and Poiana Braşov, 13-20, 2005sration of 3D space, time and scale, Geographic Information Science, Lect. Notes Comput. Sci., 6292, 310-324, 2010.

Popa, A.: Photography as Exercise of Memory in Order to Reassess, Recompose and Revive Landscapes, in: Planning and Designing Sustainable and Resilient Landscapes, edited by: Bostenaru Dan, M., Armas, I., and Goretti, A., Springer Netherlands, Dordrecht, 61-70, 2014.

Raschky, P. A.: Institutions and the losses from natural disasters, Nat. Hazards Earth Syst. Sci., 8, 627-634, doi:10.5194/nhess-8627-2008, 2008

Romano, C.: Gli edifici del periodo razionalista in Italia: Modello per la valutazione della vulnerabilità sismica, $\mathrm{PhD}$ thesis, Sapienza University, Rome, 2014.

Salewski, C.: Dr. Strangelove, I Presume - On the relation between scenarios and paranoia, in: Tickle your catastrophe, edited by: Le Roy, F., Wynants, N., Hoens, D., and Vanderbeeken, R., Academia Press, Gent, 187-196, 2011.

Schwäbisch Hall: Häuserlexikon, http://www.schwaebischhall.de/ buergerstadt/geschichte/haeuserlexikon.html, last access: $31 \mathrm{Au}-$ gust 2015 . 
Schweier, C. and Markus, M.: Classification of Collapsed Buildings for Fast Damage and Loss Assessment, Bull. Earthq. Eng., 4, 177-192, 2006.

Schweier, C., Markus, M., and Steinle, E.: Simulation of earthquake caused building damages for the development of fast reconnaissance techniques, Nat. Hazards Earth Syst. Sci., 4, 285 293, doi:10.5194/nhess-4-285-2004, 2004.

Sitte, C.: Der Städtebau nach seinen künstlerischen Grundsätzen, 2002 New edition, Birkhäuser, Basel, 1889.

Smith, P.: Walking-Based Arts: A Resource for the Guided Tour?, Scandinavian J. Hospital. Tourism, 13, 103-114, 2013.

Sonderforschungsbereich 461: SONDERFORSCHUNGSBEREICH 461: Abschlussbericht für die Jahre 1996-2007 mit Berichtsband für die Jahre 2005-2007, Universitätsverlag Karlsruhe, Karlsruhe, 2008.

Tesser, E. Gente di Roma: an exercise of dérive by Ettore Scola, Curr. Issues Tourism, 15, 577-590, 2012.

Travis, C.: From the ruins of time and space, City, 17, 209-233, 2013.
Travis, C.: Transcending the cube: translating GIScience time and space perspectives in a humanities GIS, Int. J. Geogr. Inform. Sci., 28, 1149-1164, 2014.

URBASRISK: Urban blocks in central protected area in multiple hazard approach - assessment, mapping and strategies for risk mitigation, Case study: Bucharest destructured zone by razing occuring in the communist period, http://www.uauim.ro/ cercetare/urbasrisk/en/, last access: 29 August 2015.

WHE: World Housing Encyclopedia, see the reports on Romania/Bucharest, http://www.world-housing.net, last access: 31 August 2015.

Wieczorek, A., Schenk, G. J., Juneja, M., and Lind, C. (Eds.): Mensch. Natur. Katastrophe: Von Atlantis bis heute, Schnell \& Steiner, Mannheim, 2014.

Wiley, D.: A Walk About Rome: Tactics for Mapping the Urban Periphery, Architect. Theory Rev., 15, 9-29, 2010. 